\title{
Chemical synthesis and tyrosinase inhibitory activity of rhododendrol glycosides
}

Takehiro Iwadate ${ }^{\mathrm{a}}$, Yutaka Kashiwakura ${ }^{\mathrm{b}}$, Noriyoshi Masuoka ${ }^{\mathrm{c}}$, Yoichi Yamada ${ }^{\mathrm{d}}$, Ken-ichi Nihei ${ }^{\text {a,e, } *}$

${ }^{a}$ Department of Applied Life Science, United Graduate School of Agricultural Science, Tokyo University of Agriculture and Technology, Tokyo 183-8509, Japan

${ }^{b}$ Green Center, Fuji Steel Industry, Tochigi 328-0204, Japan

${ }^{c}$ Department of Life Science, Faculty of Science, Okayama University of Science, Okayama 700-0005, Japan

${ }^{d}$ Department of Chemistry, Faculty of Education, Utsunomiya University, Tochigi 321-0943, Japan

${ }^{e}$ Department of Applied Biological Chemistry, Faculty of Agriculture, Utsunomiya University, Tochigi 321-0943, Japan

*Corresponding author: Tel.: +81-28-649-5412; fax: +81-28-649-5401; e-mail: nihei98@cc.utsunomiya-u.ac.jp.

Keywords: tyrosinase inhibitor; rhododendrol glycoside; aldol condensation; glycosylation.

\begin{abstract}
The concise synthesis of rhododendrol glycosides 3-8, which are novel derivatives of (+)-epirhododendrin (1) and (-)-rhododendrin (2), has been achieved in six steps from benzaldehyde 9 . The key reactions include aldol condensation and trichloroacetimidate glycosylation. From biological studies, it has been determined that synthetic derivatives of $\mathbf{1}$ and $\mathbf{2}$ possess potent tyrosinase inhibitory activity. Particularly, the inhibitory activity of cellobioside $8\left(\mathrm{IC}_{50}=1.51 \mu \mathrm{M}\right)$ is six times higher than that of kojic acid. The $R$-epimers $(\mathbf{4}, \mathbf{6}$, and $\mathbf{8}$ ) possessed more potent activity than the corresponding $S$-epimers $(\mathbf{3}, \mathbf{5}$, and $\mathbf{7})$, indicating that tyrosinase inhibitory activity is significantly governed by stereochemistry of rhododendrol glycosides.
\end{abstract}


Tyrosinase (EC 1.14.18.1), a copper-containing oxidoreductase, catalyzes the enzymatic oxidation of phenol to $o$-quinone..$^{1-4}$ The generated $o$-quinone possesses high reactivity and is readily transformed via nonenzymatic and enzymatic processes into colorized biological polymers, including melanin in mammals. Although these polymers may prevent genetic injuries due to excessive exposure to UV irradiation, it results in significant deposition of pigments on the skin. The presence of the oxidation products of L-tyrosine has been linked to the demise of neurons in several neurodegenerative disorders such as Parkinson's disease and Huntington's disease. ${ }^{5,6}$ From the agricultural point of view, this browning process by tyrosinase is considered to be deleterious to the color quality of plant derived foods and beverages. ${ }^{7}$ Moreover, tyrosinase inhibition leads to preservation of biological activity in foods and medicinal plants, ${ }^{8,9}$ because a number of phenolic principles are decomposed by this widely distributed oxidoreductase. ${ }^{10-12}$ Thus, adequate control of tyrosinase activity is of considerable importance for preventing cutaneous light aging and neurodegeneration, and preserving food quality. ${ }^{13}$

Acer nikoense so-called "megusurinoki" (Japanese), is a medicinal plant grown naturally in Japan. This Aceraceae plant has been used as a folk medicine to treat eye diseases for centuries. Nagai et al, (1978) isolated (+)-epirhododendrin (1), a rhododendrol glycoside from the bark of $A$. nikoense (Fig. 1). ${ }^{14}$ The aglycon of $\mathbf{1}$ has a unique structure because of its $S$ stereogenic center, and (-)-rhododendrin (2), which is an epimer of $\mathbf{1}$ and its aglycon have been found frequently in secondary plant metabolites. ${ }^{15-19}$ Chemo- and bio-synthetic studies of the glucosides $\mathbf{1}$ and $\mathbf{2}$ have been performed by several research groups. ${ }^{20-23}$ However, the synthesis of derivatives based on the rhododendrol scaffold to furnish novel physiologically active substances has been rarely investigated to date.

The monophenol structure in glucosides $\mathbf{1}$ and $\mathbf{2}$ is potentially a good substrate for tyrosinase. ${ }^{24,25}$ In contrast, several hydrophobic alkyl resorcinols have been shown to be effective inhibitors of tyrosinase oxidation. ${ }^{26,27}$ Accordingly, the structural modification of glucosides $\mathbf{1}$ and $\mathbf{2}$ into resorcinol derivatives may provide a route to the development of novel, potent, and hydrophilic tyrosinase inhibitors. Thus, in this paper, we conducted the concise synthesis of novel rhododendrol glycosides 3-8 and evaluated and reported the results of their tyrosinase inhibitory activity.

The rhododendrol glycosides were synthesized via trichloroacetimidate or Koenigs-Knorr glycosylation from the corresponding sugar donor and aglycon (Fig. 2). Aldol condensation was an appropriate reaction for the preparation of the aglycon from acetone and benzaldehyde $9 .^{28}$ According to the plan, enone 10 was obtained in $94 \%$ yield under basic 
conditions (Scheme 1). Hydrogenation of enone 10 using a palladium ethylenediamine complex on activated carbon $[\mathrm{Pd} / \mathrm{C}(\mathrm{en})]$ as catalyst and toluene as solvent at $10{ }^{\circ} \mathrm{C}$ afforded ketone $\mathbf{1 1}$ in $80 \%$ yield that was reduced by $\mathrm{NaBH}_{4}$ to afford aglycon 12 in $98 \%$ yield. ${ }^{29}$ Notably, hydride reduction of enone $\mathbf{1 0}$ followed by hydrogenation to yield aglycon $\mathbf{1 2}$ failed because the allylic alcohol obtained in the first step was quite labile and was readily converted to the corresponding conjugated diene via dehydration. Moreover, the reduction of $\mathbf{1 0}$ with $\mathrm{NaBH}_{4}$ in the presence of $\mathrm{CoCl}_{2}$ did directly provide the desired alcohol because the reaction was sluggish and did not go to completion. ${ }^{30}$

Trichloroacetimidate glycosylation of aglycon $\mathbf{1 2}$ using imidate $\mathbf{1 3}$ as the glucosyl donor and $\mathrm{BF}_{3}$ etherate as the Lewis acid did not, unfortunately, afford the desired glycoside $\mathbf{1 4}$. The acetylated compound of aglycon 12 was obtained as the major product using silica gel column chromatography; ${ }^{31}$ however, the use of trimethylsilyl trifluoromethanesulfonate instead of $\mathrm{BF}_{3}$ etherate significantly improved the yield of glycoside $\mathbf{1 4}$ to $50 \% .^{32}$ On the other hand, Koenigs-Knorr glycosylation of aglycon 12 with 2,3,4,6-tetra- $O$-acetyl- $\alpha$-D-glucopyranosyl bromide and $\mathrm{Ag}_{2} \mathrm{CO}_{3}$ provided glycoside 14 in poor yield $(12 \%){ }^{33}$

Hydrogenolysis of glycoside 14 was achieved using a catalytic amount of $\mathrm{Pd}(\mathrm{OH})_{2}$ on activated carbon in a hydrogen atmosphere to give the desired diphenol in $82 \%$ yield and it was converted to rhododendrol glucosides $\mathbf{3}$ and $\mathbf{4}$ by transesterification with sodium methoxide in $89 \%$ yield. Consequently, glucosides $\mathbf{3}$ and $\mathbf{4}$ were synthesized as an epimeric mixture from 9 in six steps with $27 \%$ overall yield.

Next, the high performance liquid chromatography (HPLC) conditions for optimal separation of glucosides $\mathbf{3}$ and $\mathbf{4}$ were examined. After several trials, glucosides $\mathbf{3}$ and $\mathbf{4}$ were isolated using preparative reverse-phase (RP)-HPLC with an isocratic elution. ${ }^{34}$ The stereochemistry at the oxymethine of the aglycon in glucosides $\mathbf{3}$ and $\mathbf{4}$ was determined as $S$ and $R,{ }^{35}$ respectively, by comparing the ${ }^{1} \mathrm{H}$ and ${ }^{13} \mathrm{C}$ nuclear magnetic resonance (NMR) data for the new glucosides with previously reported NMR data for of glucosides $\mathbf{1}$ and $2 .{ }^{18}$

The tyrosinase inhibitory activity of glucosides $\mathbf{3}$ and $\mathbf{4}$ was tested along with that of kojic acid, a commercially available inhibitor, and glucosides $\mathbf{1}$ and $\mathbf{2}$. Because of the unavailability of enantiomerically pure $\mathbf{1}$ and $\mathbf{2}$, an epimeric mixture of these two glucosides was prepared from raspberry ketone as the starting material. The $\mathrm{NaBH}_{4}$ reduction of the benzyl ether of raspberry ketone followed by trichloroacetimidate glycosylation using $\mathrm{BF}_{3}$ etherate gave the fully protected glucosides of $\mathbf{1}$ and $\mathbf{2}$ in $43 \%$ yield in three steps. ${ }^{33}$ Glucosides 1 and $\mathbf{2}$ were then obtained in high yield (84\%, two steps) after removal of all of the protective groups using the above-described process. ${ }^{36}$ Unfortunately, glucosides $\mathbf{1}$ and 2 
could not be separated using several purification methods, such as HPLC and recrystallization.

$\mathrm{IC}_{50}$ of the mixture of glucosides $\mathbf{1}$ and $\mathbf{2}$ could not be estimated against tyrosinase oxidation even when the concentration was increased to $100 \mu \mathrm{M}$ (Table 1). ${ }^{37,38} \mathrm{The}^{\mathrm{IC}_{50}}$ values for glucosides 3 and 4 were found to be 4.72 and $2.30 \mu \mathrm{M}$, respectively, and both were more potent inhibitors than kojic acid $\left(\mathrm{IC}_{50}=9.15 \mu \mathrm{M}\right)$, although 4-hexylresorcinol, ${ }^{27} \mathrm{a}$ hydrophobic inhibitor, exhibited strong activity $\left(\mathrm{IC}_{50}=0.56 \mu \mathrm{M}\right)$. Moreover, the $\mathrm{IC}_{50}$ of 3 was twice as high as that of $\mathbf{4}$, indicating that the stereochemistry of the rhododendrol-type inhibitor played a significant role in enabling the binding of the glucosides to tyrosinase. This result prompted us to synthesize additional rhododendrol glycosides $\mathbf{5}-\mathbf{8}$ for a closer investigation of the relationship between the structure of these compounds and their tyrosinase inhibitory activity (Scheme 2).

Thus, trichloroacetimidate glycosylation of aglycon 12 with imidate 15 was carried out at low temperature $\left(-40^{\circ} \mathrm{C}\right)$ to afford xyloside 16 in $48 \%$ yield. Removal of all of the protective groups of xyloside $\mathbf{1 6}$ via hydrogenolysis and transesterification proceeded smoothly to give rhododendrol xylosides $\mathbf{5}$ and $\mathbf{6}$ as an epimeric mixture (64\%, two steps). HPLC separation of xylosides 5 and $\mathbf{6}$ was then achieved using a purification procedure similar to that employed for glucosides $\mathbf{3}$ and $\mathbf{4} .^{39,40}$

In contrast, coupling reaction between aglycon 12 and imidate 17 afforded only trace amounts of the desired cellobioside 18 when the above-mentioned reaction conditions were applied. From TLC analysis, the acetylated compound of aglycon 12 was determined to be the major product. The $\beta$-facial attack of the hydroxyl anion of aglycon $\mathbf{1 2}$ at the anomeric position of the oxocarbenium ion generated from imidate $\mathbf{1 7}$ may be inhibited by the steric hindrance of the sugar donor. ${ }^{41}$ This leads to preferential addition of the hydroxyl anion to the cationic center of the acyl oxonium ion to form the orthoester intermediate. Therefore, to obtain enough cellobioside $\mathbf{1 8}$ for the following step, two equivalents of aglycon $\mathbf{1 2}$ were used as the sugar donor. In this case, cellobioside $\mathbf{1 8}$ was obtained in $20 \%$ yield from aglycon $\mathbf{1 2}$, and the subsequent successive removal of the benzyl and acetyl groups of cellobioside $\mathbf{1 8}$ furnished rhododendrol cellobiosides $\mathbf{7}$ and $\mathbf{8}$ in $85 \%$ yield (two steps). This epimeric mixture was separated using RP-HPLC to afford the pure cellobiosides $\mathbf{7}$ and $\mathbf{8}^{42,43}$

A comparison of the $\mathrm{IC}_{50}$ values of the derivatives 3-8 clearly indicates that the $R$-epimers possessed more potent activity than the $S$-epimers (Table 1$)$. This result suggests that, regardless of the type of sugar moiety, the $R$-epimers are more effective inhibitors of the tyrosinase catalyzed oxidation reaction. To the best of our knowledge, this result is a rare 
example of tyrosinase inhibitory activity governed by the stereochemistry of the inhibitor. ${ }^{44,45}$ Moreover, it should be noted that the inhibitory activity of cellobioside $\mathbf{8}$, which was the strongest inhibitor of all of the synthetic rhododendrol derivatives, was six times higher than that of kojic acid and nearly equal to that of bibenzyl glycoside inhibitors. ${ }^{38,46}$ The hydrophilic interactions between the inhibitors and tyrosinase have not yet been investigated in detail. However, chemical modification of the sugar group via incorporation of a resorcinol-type structure in the side chain may lead to the design of novel, potent and water-soluble inhibitors for practical use.

\section{Acknowledgement}

We are grateful to Dr. Michinori Karikomi (Utsunomiya University) for assistance with measurement of the optical rotations values. This study was supported in part by JSPS KAKENHI Grant Number 23510252 and JST Adaptable and Seamless Technology transfer Program through targetdriven R\&D (A-STEP). TI is also thankful for a Grant of Utsunomiya University Exploratory Research for Young Scientists for partial support of this research.

\section{References and notes}

1. Decker, H.; Schweikardt, T.; Tuczek, F. Angew. Chem. Int. Ed. 2006, 45, 4546.

2. Solomon, E. I.; Chen, P.; Metz, M.; Lee, S.; Palmer, A. E. Angew. Chem. Int. Ed. 2001, 40, 4570.

3. Hearing, V. J.; Tsukamoto, K. FASEB J. 1991, 5, 2902.

4. Briganti, S.; Camera, E.; Pichardo, M. Pigment Cell Res. 2003, 16, 101.

5. Asanuma, M.; Miyazaki, I.; Ogawa, N. Neurotox. Res. 2003, 5, 165.

6. De Iuliis, A.; Arrigoni,G.; Anderson, L.; Zambenedetti, A.; Burlina, A.; James, P.; Arslan, P.; Vianello, F. Biochim. Biophys. Acta 2008, 1784, 1687.

7. Kubo, I.; Chen, Q. X.; Nihei, K. Food Chem. 2003, 81, 241.

8. Seo, S. Y.; Sharma, V.; Sharma, N. J. Agric. Food Chem. 2003, 51, 2837.

9. Loizzo, M. R.; Tundis, R.; Menichini, F. Compr. Rev. Food Sci. Food Saf. 2012, 11, 378.

10. Nihei, K.; Kubo, I. Bioorg. Med. Chem. Lett. 2003, 13, 51.

11. Kubo, I.; Nihei, K.; Shimizu, K. Bioorg. Med. Chem. 2004, 12, 5343.

12. Kubo, I.; Nihei, K.; Tsujimoto, K. Bioorg. Med. Chem. 2004, 12, 5349.

13. Cheng, T. S. Int. J. Mol. Sci. 2009, 10, 2440.

14. Inoue, T.; Ishidate, Y.; Fujita, M.; Kubo, M.; Fukushima, M.; Nagai, M. Yakugaku Zasshi 
1978, 98, 41.

15. Archangelsky, K. Arch. Exp. Pathol. Pharmakol. 1901, 46, 313.

16. Santamour, F. S.; Lundgren. L. N. Biochem. Syst. Ecol. 1994, 25, 335.

17. Parmar, V. S.; Vardhan, A.; Taneja, P.; Sinha, R.; Patnaik, G. K.; Tripathi, S. C.; Boll, P. M.; Larsen, S. J. Chem. Soc. Perkin Trans. 1 1991, 2687.

18. Pan, H.; Lundgren L. N. Phytochemistry 1994, 36, 79.

19. Kim, M.; Nugroho, A.; Chio, J.; Park, J. H.; Park, H. Arch. Pharm. Res. 2011, 34, 971.

20. Mori, K.; Qian, Z. Bull. Soc. Chim. Fr. 1993, 130, 382.

21. Klischies, M.; Zenk, M. H. Phytochemistry 1978, 17, 1281.

22. Fujita, T.; Hatamoto, H.; Iwasaki, T.; Takafuji, S. Phytochemistry 1995, 39, 1085.

23. Shimoda, K.; Harada, T.; Hamada, H.; Nakajima, N.; Hamada, H. Phytochemistry 2007, $68,487$.

24. Rolff, M.; Schottenheim, J.; Decker, H.; Tuczek F. Chem. Soc. Rev. 2011, 40, 4077.

25. Espín, J. C.; Varón, R.; Fenoll, L. G.; Gilabert, M. A.; García-Ruíz, P. A.; Tudela, J.; García-Cánovas, F. Eur. J. Biochem. 2000, 267, 1270.

26. Khatib, S.; Nerya, O.; Musa, R.; Shmuel, M.; Tamir, S.; Vaya, J. Bioorg. Med. Chem. 2005, $13,433$.

27. Dawley, R. M.; Flurkey, W. H. J. Food Sci. 1993, 58, 609.

28. Shi, J.; Liu, Y.; Wang, M.; Lin, L, Lin. X.; Feng, X. Tetrahedron 2011, 67, 1781.

29. Sajiki, H.; Hattori, K.; Hirota, K. J. Org. Chem. 1998, 63, 7990.

30. Aramini, A.; Brinchi, L.; Germani, R.; Savelli, G. Eur. J. Org. Chem. 2000, 1793.

31. Kondo, T.; Oyama, K.; Nakamura, S.; Yamakawa, D.; Tokuno, K.; Yoshida, K. Org. Lett. 2006, 16, 3609.

32. Schmidt, R. R. Angew. Chem., Int. Ed. Engl. 1986, 25, 212.

33. Huang, L. -J.; Hou, S. -J.; Li, J. -B.; Yu, D. -Q. J. Asian Nat. Prod. Res. 2007, 9, 223.

34. The use of a Wakosil-II 5C18 AR Prep column $(4.6 \mathrm{~mm} \times 250 \mathrm{~mm})$ with $12 \% \mathrm{MeCN}^{-\mathrm{H}_{2} \mathrm{O}}$ as the eluting solvent and a flow rate of $1.0 \mathrm{~mL} / \mathrm{min}$ at room temperature led to the best separation results $\left(3: t_{\mathrm{R}}=9.5 \mathrm{~min}, \mathbf{4}: t_{\mathrm{R}}=8.7 \mathrm{~min}\right)$. Glucosides 3 and $\mathbf{4}$ could also be separated using Inertsil ODS-3, Symmetry C-18 and Capcell Pak C18 MG RP-HPLC columns. Isolated yields of $\mathbf{3}$ and $\mathbf{4}$ were $24 \%$ and $28 \%$, respectively.

35. Compound 3: colorless solid; $[\alpha]^{26}{ }_{\mathrm{D}}-21.8$ ( $\left.c 0.43, \mathrm{MeOH}\right)$; IR (film) $v_{\max } 3508,1622$, $1074 \mathrm{~cm}^{-1} ;{ }^{1} \mathrm{H}$ NMR $\left(400 \mathrm{MHz}, \mathrm{CD}_{3} \mathrm{OD}\right) \delta 6.89(\mathrm{~d}, \mathrm{~J}=8.2 \mathrm{~Hz}, 1 \mathrm{H}, \mathrm{H}-6), 6.26(\mathrm{~d}, \mathrm{~J}=$ 2.4Hz, 1H, H-3'), 6.21 (dd, J = 8.2, 2.4Hz, 1H, H-5'), 4.35 (d, J = 7.8 Hz, 1H, H-1"), 3.84 (dd, J = 11.9, 2.3 Hz, 1H, H-6"), 3.84-3.79 (m, 1H, H-2), 3.66 (dd, J = 11.9, 5.4 Hz, 1H, 
H-6"), 3.37-3.16 (m, 4H, H-2"-H-5"), 2.65-2.52 (m, 2H, H-4) 1.89-1.64 (m, 2H, H-3), 1.27 (d, J = 6.2 Hz, 3H, H-1); ${ }^{13} \mathrm{C}$ NMR (100 MHz, CD $\left.3 \mathrm{OD}\right) \delta 157.3$ (s, C-4'), 156.9 (s, C-2'), 131.5 (d, C-6'), 121.0 (s, C-1'), 107.4 (d, C-5'), 104.0 (d, C-3), 103.5 (d, C-1"), 78.1 (d, C-3"), 77.8 (d, C-5"), 77.5 (d, C-2), 75.4 (d, C-2"), 71.6 (d, C-4"), 62.7 (t, C-6"), 38.3 (t, C-4), 26.4 (t, C-3), 22.1 (q, C-1); ESIMS m/z 343.14 [M-H]'.

Compound 4: colorless solid; $[\alpha]^{27}$ D -36.6 ( $c$ 0.23, MeOH); IR (film) $v_{\max } 3424,1622$, $1074 \mathrm{~cm}^{-1}$; ${ }^{1} \mathrm{H}$ NMR (400 MHz, CD $\left.3 \mathrm{OD}\right) \delta 6.90(\mathrm{~d}, \mathrm{~J}=8.1 \mathrm{~Hz}, 1 \mathrm{H}, \mathrm{H}-6$ ) $) 6.25$ (d, J = 2.4Hz, 1H, H-3'), 6.20 (dd, J = 8.1, 2.4Hz, 1H, H-5'), 4.34 (d, J = 7.8 Hz, 1H, H-1"), 3.93-3.88 (m, 1H, H-2), 3.87 (dd, J = 11.9, 2.4 Hz, H-6"), 3.70 (dd, J = 11.9, 5.4 Hz, 1H, H-6"), 3.38-3.16 (m, 4H, H-2"-H-5"), 2.66-2.49 (m, 2H, H-4) 1.89-1.64 (m, 2H, H-3), $1.21(\mathrm{~d}, \mathrm{~J}=6.2 \mathrm{~Hz}, 3 \mathrm{H}, \mathrm{H}-1) ;{ }^{13} \mathrm{C}$ NMR (100 MHz, CD $\left.{ }_{3} \mathrm{OD}\right) \delta 157.3$ (s, C-4'), 156.9 (s, C-2'), 131.5 (d, C-6'), 122.0 (s, C-1'), 107.4 (d, C-5'), 104.0 (d, C-3'), 102.2 (d, C-1"), 78.1 (d, C-3"), 77.8 (d, C-5"), 75.7 (d, C-2), 75.1 (d, C-2"), 71.7 (d, C-4") 62.8 (t, C-6"), 38.8 (t, C-4), 26.5 (t, C-3), 20.0 (q, C-1); ESIHRMS m/z 343.1388 [M-H] (calcd for $\mathrm{C}_{16} \mathrm{H}_{23} \mathrm{O}_{8}$, 343.1393).

36. All spectra data of $\mathbf{1}$ and $\mathbf{2}$ are consisted with those as previously reported. ${ }^{18}$

37. The assay was performed as previously reported. ${ }^{38}$ Briefly, mushroom tyrosinase purchased from Sigma-Aldrich was used in this experiment. First, $0.1 \mathrm{~mL}$ of the DMSO solution of the inhibitor was mixed with $0.3 \mathrm{~mL}$ of a $5.0 \mathrm{mM}$ of L-DOPA aqueous solution, $0.6 \mathrm{~mL}$ of $0.25 \mathrm{M}$ sodium phosphate buffer $(\mathrm{pH} 6.8)$ and $1.9 \mathrm{~mL}$ of water, incubated at $30{ }^{\circ} \mathrm{C}$ for $5 \mathrm{~min}$. Then, $0.1 \mathrm{~mL}$ of enzyme solution was added to the mixture. This solution was immediately monitored for the formation of dopachrome by measuring the linear increase in optical density $(475 \mathrm{~nm})$ at $30{ }^{\circ} \mathrm{C}$.

38. Tajima, R.; Oozeki, H.; Muraoka, S.; Tanaka, S.; Motegi, Y.; Nihei, H.; Yamada, Y.; Masuoka, N.; Nihei, K. Eur. J. Med. Chem. 2011, 46, 1374.

39. The separation procedure for 3 and 4 was applied, ${ }^{34}$ except that $15 \% \mathrm{MeCN}-\mathrm{H}_{2} \mathrm{O}$ was used as the eluting solvent $\left(\mathbf{5}: t_{\mathrm{R}}=9.5 \mathrm{~min}, \mathbf{6}: t_{\mathrm{R}}=7.7 \mathrm{~min}\right)$. Isolated yields of 5 and $\mathbf{6}$ were $41 \%$ and $32 \%$, respectively.

40. Compound 5: colorless solid; $[\alpha]^{27}$ D -21.4 (c 0.26, MeOH); IR (film) $v_{\max } 3418,1622$, $1048 \mathrm{~cm}^{-1} ;{ }^{1} \mathrm{H}$ NMR $\left(400 \mathrm{MHz}, \mathrm{CD}_{3} \mathrm{OD}\right) \delta 6.88(\mathrm{~d}, \mathrm{~J}=8.2 \mathrm{~Hz}, 1 \mathrm{H}, \mathrm{H}-6)$ ) 6.27 (d, J = 2.4 Hz, 1H, H-3'), 6.22 (dd, J = 8.2, 2.4 Hz, 1H, H-5'), 4.29 (d, J = 7.6 Hz, 1H, H-1"), 3.84 (dd, $\mathrm{J}=11.4,5.3 \mathrm{~Hz}, 1 \mathrm{H}, \mathrm{H}-5 "), 3.74$ (sext, J = 6.2 Hz, 1H, H-2), 3.66 (ddd, J = 10.3, 8.9, 5.3 Hz, 1H, H-4"), 3.33-3.29 (m, 1H, H-3"), 3.17 (dd, 1H, J = 9.4, 7.6 Hz, H-2"), 3.16 (dd, J = 11.4, 10.3 Hz, 1H, H-5"), 2.64-2.52 (m, 2H, H-4) 1.89-1.63 (m, 2H, H-3), 1.24 (d, J = 6.2 
$\mathrm{Hz}, 3 \mathrm{H}, \mathrm{H}-1)$ ) ${ }^{13} \mathrm{C}$ NMR (100 MHz, CD $\left.3 \mathrm{OD}\right) \delta 157.3$ (s, C-4'), 156.9 (s, C-2'), 131.5 (d, C-6'), 121.0 (s, C-1'), 107.4 (d, C-5'), 104.8 (d, C-1"), 103.5 (d, C-3'), 78.9 (d, C-3"), 77.7 (d, C-2), 75.2 (d, C-2"), 71.2 (d, C-4"), 66.8 (t, C-5"), 38.6 (t, C-4), 26.4 (t, C-3), 22.1 (q, C-1); ESIHRMS m/z 313.1270 [M-H] (calcd for $\mathrm{C}_{15} \mathrm{H}_{21} \mathrm{O}_{7}, 313.1287$ ).

Compound 6: colorless solid; $[\alpha]^{26}{ }_{\mathrm{D}}-9.3\left(c\right.$ 0.70, MeOH); IR (film) $v_{\max } 3468,1684$, 1094, $824 \mathrm{~cm}^{-1} ;{ }^{1} \mathrm{H}$ NMR (400 MHz, CD 3 OD) $\delta 6.86$ (d, J = 8.2 Hz, 1H, H-6'), 6.26 (d, J = 2.4 Hz, 1H, H-3'), 6.20 (dd, J = 8.2, 2.4 Hz, 1H, H-5'), 4.28 (d, J = 7.6 Hz, 1H, H-1"), 3.86 (dd, J = 11.4, $5.3 \mathrm{~Hz}, 1 \mathrm{H}, \mathrm{H}-5 "), 3.82$ (m, 1H, H-2), 3.50 (ddd, J = 10.2, 8.9, $5.3 \mathrm{~Hz}, 1 \mathrm{H}$, H-4"), 3.34-3.29 (m, 1H, H-3"), 3.19 (m, 1H, H-5"), 3.17 (dd, 1H, H-2"), 2.61, 2.49 (ddd, $2 \mathrm{H}, 13.7,9.8,5.8 \mathrm{~Hz}, \mathrm{H}-4), 1.84-1.63$ (m, 2H, H-3), 1.20 (d, J = 6.2 Hz, 3H, H-1). ${ }^{13} \mathrm{C}$ NMR (100 MHz, CD $\left.{ }_{3} \mathrm{OD}\right) \delta 157.2$ (s, C-4'), 156.9 (s, C-2'), 131.4 (d, C-6'), 121.1 (s, C-1'), 107.3 (d, C-5'), 103.5 (d, C-3'), 103.0 (d, C-1"), 77.9 (d, C-3"), 75.9 (d, C-2), 74.9 (d, C-2"), 71.3 (d, C-4") 66.9 (t, C-5"), 38.8 (t, C-4), 26.6 (t, C-3), 20.0 (q, C-1); ESIMS m/z $313.14[\mathrm{M}-\mathrm{H}]^{-}$.

41. Kong, F. Carbohydr. Res. 2007, 342, 345.

42. The separation procedure for 3 and 4 was applied, ${ }^{34}$ except that $10 \% \mathrm{MeCN}-\mathrm{H}_{2} \mathrm{O}$ was used as the eluting solvent $\left(\mathbf{7}: t_{\mathrm{R}}=14.2 \mathrm{~min}, \mathbf{8}: t_{\mathrm{R}}=13.2 \mathrm{~min}\right)$. Isolated yields of $\mathbf{7}$ and $\mathbf{8}$ were $35 \%$ and $38 \%$, respectively.

43. Compound 7: colorless solid; $[\alpha]^{26}$-15.4 (c 0.27, MeOH); IR (film) $v_{\max } 3418,1639$, $1024 \mathrm{~cm}^{-1}$; ${ }^{1} \mathrm{H}$ NMR (400 MHz, CD 3 OD) $\delta 6.89(\mathrm{~d}, \mathrm{~J}=8.2 \mathrm{~Hz}, 1 \mathrm{H}, \mathrm{H}-6$ '), 6.25 (d, J = 2.4 Hz, 1H, H-3'), 6.21 (dd, J = 8.2, 2.4 Hz, 1H, H-5'), 4.42 (d, J = 7.8 Hz, 1H, H-1"), 4.38 (d, $\left.\mathrm{J}=7.8 \mathrm{~Hz}, 1 \mathrm{H}, \mathrm{H}-1^{\prime \prime \prime}\right), 3.88$ (dd, J = 11.8, 1.7 Hz, 1H, H-6"), 3.89-3.85 (m, 2H, H-6", H-6"'), 3.80 (sext, J = 6.2 Hz, H-2), 3.66 (dd, J = 11.8, 5.4 Hz, 1H, H-6'"), 3.57 (t, J = 9.1 Hz, H-3"), 3.51 (t, J = 8.8 Hz, H-3"'), 3.39-3.32 (m, 4H, H-4", H-4"', H-5", H-5"'), 3.26-3.20 (m, 2H, H-2", H-2"'), 2.65-2.53 (m, 2H, H-4) 1.89-1.63 (m, 2H, H-3), 1.27 (d, $\mathrm{J}=6.2 \mathrm{~Hz}, 3 \mathrm{H}, \mathrm{H}-1) ;{ }^{13} \mathrm{C} \mathrm{NMR}\left(100 \mathrm{MHz}, \mathrm{CD}_{3} \mathrm{OD}\right) \delta 157.4$ (s, C-4'), 156.9 (s, C-2'), 131.5 (d, C-6'), 121.0 (s, C-1'), 107.4 (d, C-5'), 104.6 (d, C-3'), 103.8 (d, C-1'"), 103.5 (d, C-1"), 80.7 (d, C-4"), 78.1 (d, C-5'"), 77.9 (d, C-5"), 77.5 (d, C-2), 76.5 (d, C-3"'), 76.3 (d, C-3"), 75.1 (d, C-2"'), 74.9 (d, C-2"), 71.4 (d, C-4"'), 62.4 (t, C-6"'), 61.9 (t, C-6"), 38.2 (t, C-4), 26.4 (t, C-3), 22.1 (q, C-1); ESIMS m/z 505.19 [M-H]'.

Compound 8: colorless solid; $[\alpha]^{25}$ D -35.1 ( $c$ 0.26, MeOH); IR (film) $v_{\max } 3383,2952$, 1621, 1066, $1026 \mathrm{~cm}^{-1}$; ${ }^{1} \mathrm{H}$ NMR (400 MHz, CD 3 OD) $\delta 6.90$ (d, J = $8.2 \mathrm{~Hz}, 1 \mathrm{H}, \mathrm{H}-6$ '), 6.25 (d, J = 2.4 Hz, 1H, H-3'), 6.20 (dd, J = 8.2, 2.4 Hz, 1H, H-5'), 4.43 (d, J = 7.8 Hz, 1H, H-1"), 4.37 (d, J = 7.8 Hz, 1H, H-1"'), 3.89-3.86 (m, 4H, H-2, H-6", H-6"), 3.66 (dd, J = 
11.8, 5.4 Hz, H-6"'), 3.60 (dd, J = 9.1, 9.0 Hz, H-3"), 3.52 (t, J = 8.9 Hz, H-3"'), 3.40-3.32 (m, 4H, H-4", H-4"', H-5", H-5"'), 3.28-3.20 (m, 2H, H-2", H-2'"), 2.62, 2.53 (ddd, J = 13.8, 9.4, $5.8 \mathrm{~Hz}, 2 \mathrm{H}, \mathrm{H}-4)$ 1.89-1.65 (m, 2H, H-3), 1.21 (d, J = 6.2 Hz, 3H, H-1); ${ }^{13} \mathrm{C}$ NMR (100 MHz, CD $\left.{ }_{3} \mathrm{OD}\right) \delta 157.3$ (s, C-4'), 156.9 (s, C-2'), 131.5 (d, C-6'), 121.1 (s, C-1'), 107.4 (d, C-5'), 104.5 (d, C-1"'), 104.6 (d, C-3'), 102.2 (d, C-1"), 80.4 (d, C-4"), 78.1 (d, C-5'"), 77.9 (d, C-5"), 76.5 (d, C-3"'), 76.4 (d, C-3"), 75.8 (d, C-2), 75.0 (d, C-2"), 74.8 (d, C-2"'), 71.4 (d, C-4"'), 62.4 (t, C-6"'), 62.0 (t, C-6"'), 38.7 (t, C-4), 26.5 (t, C-3), 20.0 (q, C-1); ESIHRMS m/z 505.1921 [M-H] ${ }^{-}$(calcd for $\mathrm{C}_{22} \mathrm{H}_{33} \mathrm{O}_{13}, 505.1921$ ).

44. Funayama, M.; Arakawa, H.; Yamamoto, R.; Nishino, T.; Shin, T.; Murao, S. Biosci. Biotech. Biochem. 1995, 59, 143.

45. Nakashima, S.; Matsuda, H.; Oda, Y.; Nakamura, S.; Xu, F.; Yoshikawa, M. Bioorg. Med. Chem. 2010, 18, 2337.

46. Oozeki, H.; Tajima, R.; Nihei, K. Bioorg. Med. Chem. Lett. 2008, 18, 5252. 
Table 1

Tyrosinase inhibitory activities of rhododendrol glucosides 1-8, kojic acid, and 4-hexylresorcinol

\begin{tabular}{cc}
\hline Compounds tested & $\mathrm{IC}_{50}(\mu \mathrm{M})^{\mathrm{a}}$ \\
\hline $\mathbf{1}$ and $\mathbf{2}$ & $>100$ \\
$\mathbf{3}$ & $4.72 \pm 0.58$ \\
$\mathbf{4}$ & $2.30 \pm 0.15$ \\
$\mathbf{5}$ & $4.56 \pm 0.48$ \\
$\mathbf{6}$ & $1.72 \pm 0.17$ \\
$\mathbf{7}$ & $3.83 \pm 0.45$ \\
$\mathbf{8}$ & $1.51 \pm 0.10$ \\
Kojic acid & $9.15 \pm 0.71$ \\
4-Hexylresorcinol & $0.56 \pm 0.02$ \\
\hline${ }^{\mathrm{a}}$ The IC & (50 values represent means $\pm \mathrm{SE}$ of \\
three different experiments.
\end{tabular}




\section{Legends to the figure and schemes}

Figure 1. Structure of rhododendrol glycosides 1-8.

Figure 2. Synthetic plan for rhododendrol glycosides.

Scheme 1. Synthesis of rhododendrol glucosides 3 and 4 .

Scheme 2. Synthesis of rhododendrol glycosides 5-8. 

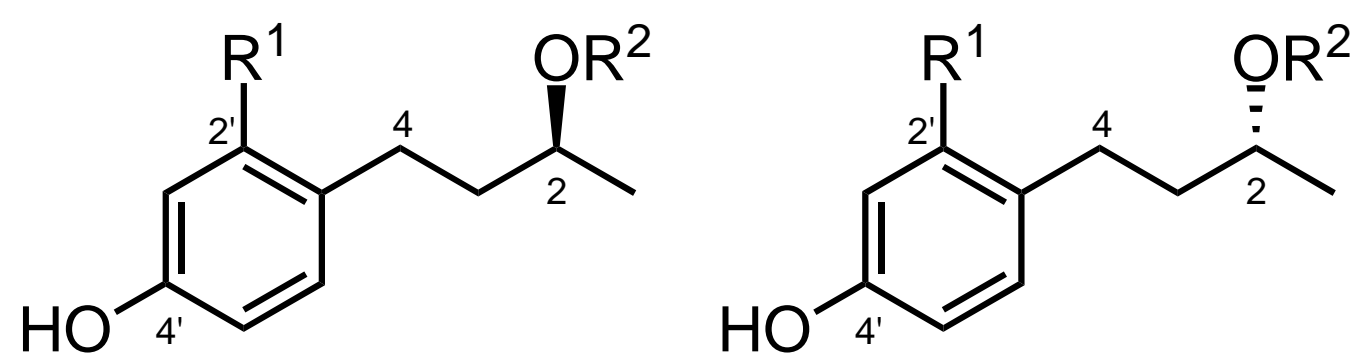

1: $R^{1}=H, R^{2}=$ Glc

3: $R^{1}=O H, R^{2}=$ Glc

2: $R^{1}=H, R^{2}=G l c$

5: $\mathrm{R}^{1}=\mathrm{OH}, \mathrm{R}^{2}=\mathrm{Xyl}$

4: $\mathrm{R}^{1}=\mathrm{OH}, \mathrm{R}^{2}=\mathrm{Glc}$

7: $\mathrm{R}^{1}=\mathrm{OH}, \mathrm{R}^{2}=\mathrm{Cel}$

6: $\mathrm{R}^{1}=\mathrm{OH}, \mathrm{R}^{2}=\mathrm{Xyl}$

8: $\mathrm{R}^{1}=\mathrm{OH}, \mathrm{R}^{2}=\mathrm{Cel}$

Figure 1. K. Nihei 


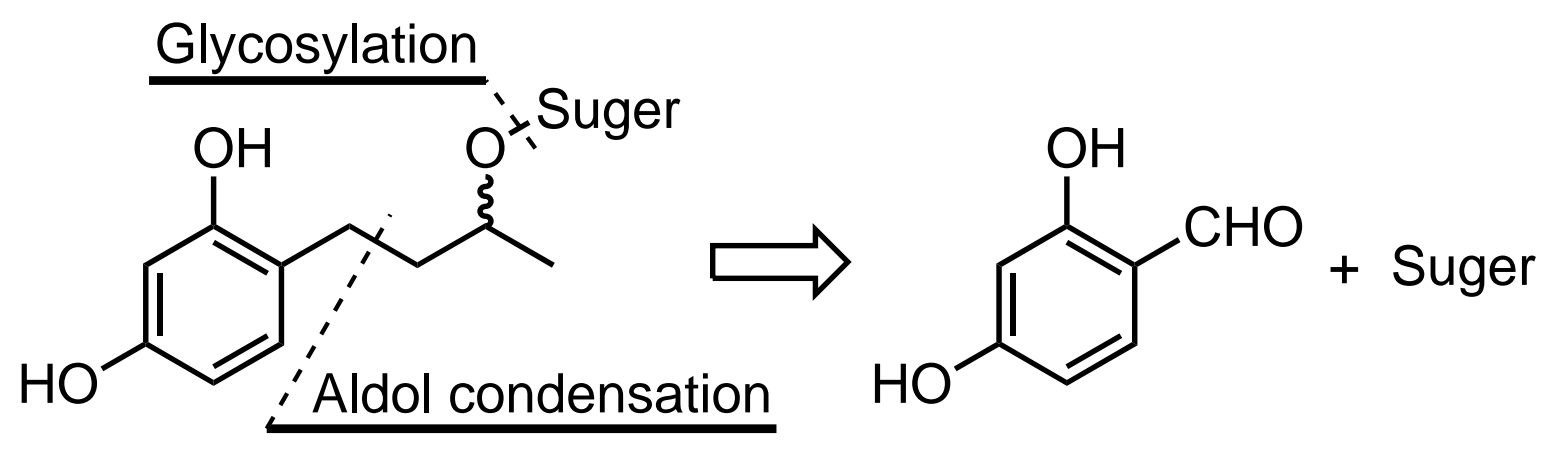

Figure 2. K. Nihei 


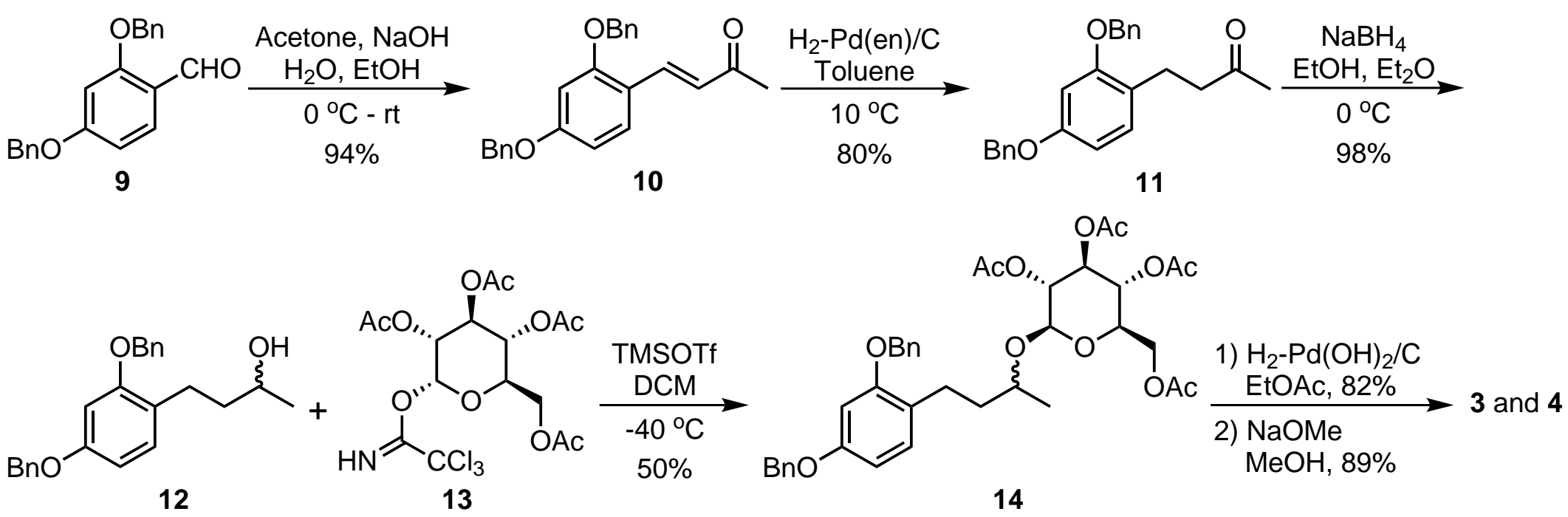



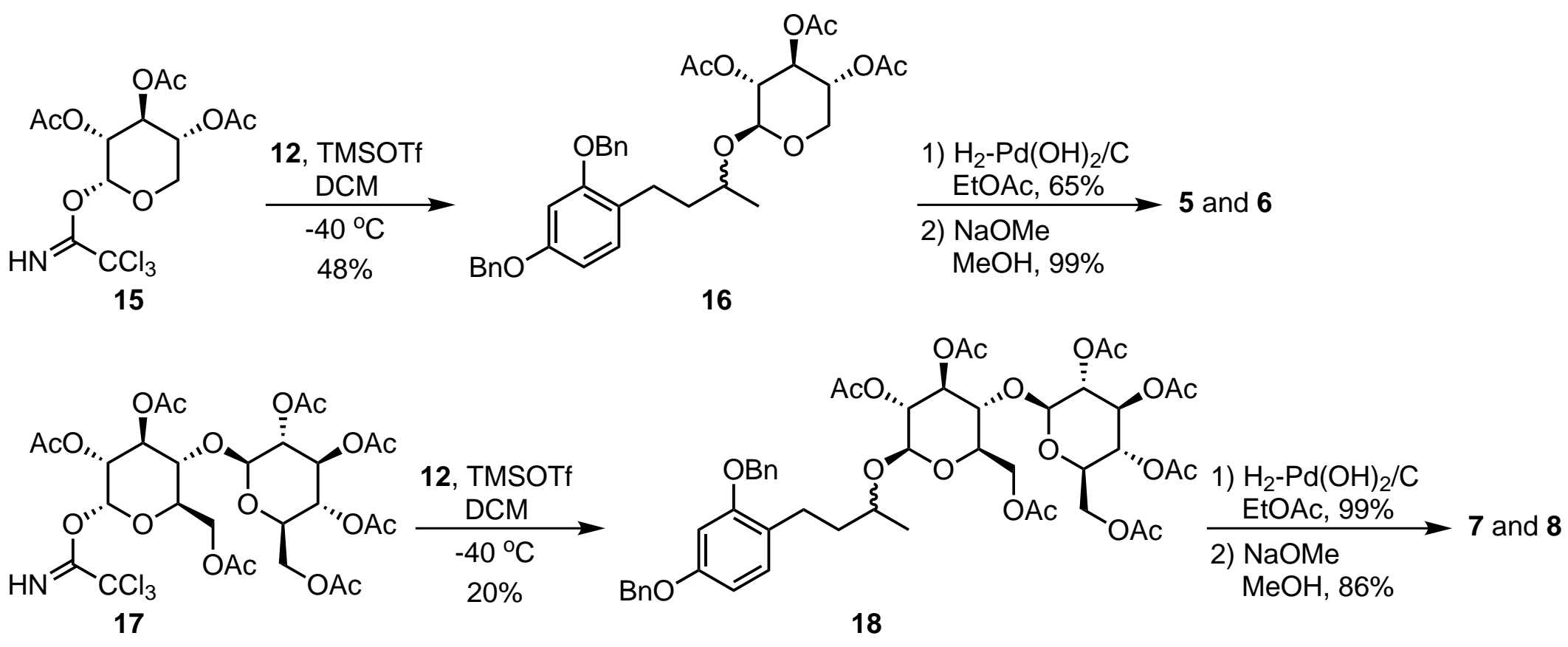
Graphical Abstract

\section{Chemical synthesis and tyrosinase inhibitory activity of rhododendrol glycosides}

Takehiro Iwadate, Yutaka Kashiwakura, Noriyoshi Masuoka, Yoichi Yamada, Ken-ichi Nihei*<smiles>COC(C)CCc1ccc(O)cc1O</smiles>

$\mathrm{IC}_{50}=4.75 \mu \mathrm{M}$<smiles>COC(C)CCc1ccc(O)cc1O</smiles>

$\mathrm{IC}_{50}=2.30 \mu \mathrm{M}$ 